\title{
Information system of the rare endangered plants in Poyang Lake watershed
}

\author{
Wenli He, Xingzhao Dai, Xinghua Le, Yu Fang, Bangyou Yan, Haiou Bao \\ a Mountain-River-Lake Development management committee office, Nanchang, 330046, China \\ Email: lexinghua@sina.com
}

Keywords: Endangered plants; Data bank; System design

\begin{abstract}
According to original environment destroy of the precious endangered plants, the information system need be built to monitor the endangered plants. Here, using $\mathrm{C}++$, combined with Arcobject soft to establish the management platform system. The main design is data bank design and user interface design. In order to satisfy the project requirement, the data design should come with the survey data. The interface design should come with the special person. The data bank needs to fit the local environment, the local position, the local background image. At last, endangered plants information system is developed.
\end{abstract}

\section{Introduction}

Poyang Lake watershed is a large scale watershed which has the whole eco-system. The terrain in the watershed is complicated. The diversity of plant is rich. The whole area belongs to subtropical humid monsoon climate[1,2].

However, in the recent years, with the development of the local economy, the human actions have a great affection on the original environment of the original plants, plus the natural disaster happens[3]. It leads to decreasing of lots of precious plants. Some even goes to die out[4]. In order to protect the plants resources, it is necessary to survey the environment of the precious plants. It is also important to develop the information system platform to monitor the original environment of the plants for a long period.

Then, the mountain-river-lake office associates with Lushan botanical garden in Jiangxi province and the other relevant sections to establish the precious endangered plants data bank and the corresponding information system. After the rural countries survey, preparation of specimen, combined with the technology of remote sensing and GIS, Mountain-river-lake office tries to develop the precious endangered plants data information platform by $\mathrm{C}++$ language and Arcobject soft. The platform will be used to monitor the environment of plants and their status. It will be convenient for researcher to study the change of endangered plants.

Up to now, the project group had already prepared many thousands of specimens. They also surveyed many important conservation areas on the endangered plants. The basic information of endangered plants had been built. In this paper, the data bank and information system of endangered plants in Poyang Lake watershed designs to show how to monitor the environment of endangered plants.

\section{Data area}

Poyang lake watershed lies to the south of Yangtze river middle and lower reaches in the south-east of China. The north altitude locates between24.5 and 30.01degree. The east longitude locates between 113.51 and 118.50 degree. The whole figure looks like a fish. South to the Poyang Lake watershed is Guangdong province. Southeast is Fujian province. Northeast is Zhejiang province. West is Hunan province. The whole watershed area is about 168,000 km2. The whole watershed terrain combines with mountain area, mound, hillock, terrace, plain, river, lake, Swamp, sand and other landforms. Different terrains covered different botany.

According to the recent survey data, the whole watershed have about 5117 kinds of higher plants, 
which contents 8 families of Gymnosperms, 22 genera, 31 species and 210 families of angiosperm, 1340 genera, 4088 species. Gymnosperm is about 15\% of the total species in China. Angiosperm is about $17 \%$ of the total species in China.

According to the statistics of the book National Key Protection Wild Plants List (the first phrase and the second phrase) and the book China Species Red list (the first Volume), there are 57 families of wild rare and endangered species of higher plants, 128 genera, 207 species in Poyang Lake watershed, which is about $4 \%$ higher plants in the watershed[5]. Among the higher plants, there are Pteridophyta and spermatophyte. Pteridophyta have 4 families of ferns, 5 genera, 7 species. Spermatophyte separates into gymnospermae and angiospermae. The gymnospermae have 8 families, 18 genera, 28 species. The angiospermae have 45 families, 105 genera, 172 species[6].

\section{Design of data bank}

A rare and endangered plant database of Poyang Lake watershed requires a large number of basic data to support, which combined with some professional data to display. Therefore, there will be some vector data, raster data and some other information. These data will often appear in the following file format:

Tab1. Statistical tables of the rare and endangered plant database file format

\begin{tabular}{|c|c|c|c|}
\hline File format & type & Use & describe \\
\hline Shp & vector data & Map or position & $\begin{array}{c}\text { Boundary, spot, } \\
\text { survey area and so on }\end{array}$ \\
\hline Img 、 Tif & $\begin{array}{l}\text { raster data（including } \\
\text { coordinate information） }\end{array}$ & $\begin{array}{l}\text { Background } \\
\text { images }\end{array}$ & Vegetation cover \\
\hline Jpg & raster data & $\begin{array}{l}\text { Plants photo or } \\
\text { species photo }\end{array}$ & Single plant close up \\
\hline Execel & tables & $\begin{array}{l}\text { Plant type } \\
\text { information }\end{array}$ & $\begin{array}{l}\text { Classification or } \\
\text { statistics }\end{array}$ \\
\hline Word & document & $\begin{array}{c}\text { The other } \\
\text { document info }\end{array}$ & $\begin{array}{c}\text { Close up } \\
\text { description of material }\end{array}$ \\
\hline
\end{tabular}

\section{The database content}

According to the collected data and the content of the data, combined with the functional development of the rare and endangered plants in Poyang Lake watershed, the rare and endangered plant database of Poyang Lake river basin is classified into the following categories:

A. specimen Gallery

In the process of rare and endangered plants in Poyang Lake River Basin, it is necessary to compare the plant information in the past with the future. It is necessary to make a sample of endangered plants. A large number of samples were collected, and some samples were collected in the library, including sample collection area, personnel, collection time and so on.

B. positioning data

The position information of the point elements is mainly the position information of linear elements. In the process of project implementation, some specimen collection points, field soil sampling points are recorded, and the distribution of the plant is recorded by linear or surface.

C. background data

Basemap background is divided into two categories, one is based on the remote sensing image raster data, the other is to map line designated description vector data. Remote sensing image can be in different years, data of different periods can also be different spatial resolution of the data, can also be access to different sensor image. Vector data is mainly the administrative boundaries of Jiangxi Province, all the natural protection areas, the province's DEM related data.

D. plant information data (rank, name)

According to plant classification method, plants are classified into different genera, species, according to the existing plant number and frequency and other plants, according to a rule (such as 
endangered state, or protection level, etc.), the plant is divided into different levels.

Different plant habitat information is different. The plant's habitat information mainly includes soil, altitude, humidity, temperature and other physical quantities, habitat information mainly through the survey and data analysis.

\section{Relationship between the database}

The four kinds of databases are connected with each other, and they are related to the information of the plant. They also contain information about the plant. They also contain the information of the map, and there are also some information. There is a relationship between them. Therefore, when the data is changed into other interfaces, it is considered that the data is directly related to the different interfaces.

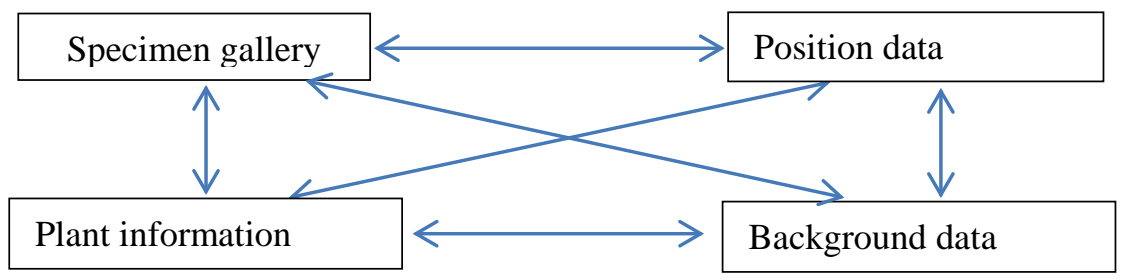

Fig. 1 The relational graph between the database

\section{The main structure of the database}

A. specimen information base:

Specimen database to the system of plant specimens, collection, acquisition, date, the corresponding subject, species, rank, place names, habitat, photo, etc., specific data items as follows:

\begin{tabular}{|l|l|l|l|l|l|l|l|l|}
\hline Plant name & person & number & Collect date & position & altitude & species & habitat & $\ldots$ \\
\hline Ginkgo biloba & & & & & & & & \\
\hline Taxus wallichiana & & & & & & & & \\
\hline$\ldots$ & & & & & & & & \\
\hline
\end{tabular}

B. location database

Positioning database to record the location, positioning time, the latitude and longitude of the area, under the area, detailed location, specific work, staff, etc., specific data items are as follows

\begin{tabular}{|l|l|l|l|l|l|l|l|}
\hline \multicolumn{1}{|c|}{ Event } & date & coordinate & country & address & Specification operate & person & $\ldots$ \\
\hline Specimens collect & & & & & & & \\
\hline Soil collect & & & & & & & \\
\hline Survey route & & & & & & & \\
\hline ... & & & & & & & \\
\hline
\end{tabular}

C. map background database

Map data all adopt uniform projection, due to inconsistent image resolution and accuracy of vector map making inconsistent, in use process need to control can display the scale range, beyond the scope of no longer displays the map background, and other map background substitution. The map display is given priority principle, consider the overlay, in consideration of the mutual dilution and fusion.

\begin{tabular}{|l|l|c|c|c|}
\hline \multicolumn{1}{|c|}{ Data name } & Type & scales & content & remarks \\
\hline Image of Poyang Lake watershed & raster & $1: 100,000-1: 1,500,000$ & 4 bands & \\
\hline Image of Gangjiang reserve $)$ & raster & $1: 2000-1: 100,000$ & & \\
\hline Boundary 1 & vector & $1: 100,000-1: 1,500,000$ & & \\
\hline$\ldots . .$. & & & & \\
\hline
\end{tabular}

D. plant information database

Plant information is mainly derived from the survey report of the protected areas, the project's own investigation, the past survey data collected. As a result of the investigation report station in different perspectives on plant information data, most of the original data retention, but also some 
through integration, to generate some data.

\begin{tabular}{|c|l|l|l|l|l|}
\hline Chinese name & \multicolumn{1}{|c|}{ Latin name } & & \multicolumn{1}{c|}{ area } & rank & $\ldots$ \\
\hline Yinxin & Ginkgo biloba & IUCN red book & Lushan reserve & EN & \\
\hline Minnan & Phoebe bournei & Chinese specimens red book & Wuyi reserve & VU & \\
\hline Bizisanjianshan & Cephalotaxus oliveri & Chinese specimens red book & Guanshan & VU & \\
\hline Xiangguoshu & Emmenopterys henryi & IUCN red book & Jiulingshan & VU & \\
\hline$\ldots$ & & & & \\
\hline
\end{tabular}

\section{Design of information platform}

According to the project requirements, the platform should have these functions. The functions are system management function, Information query function, Information editing function, Layer calling function, Table processing function, positioning function. All the function should be easy to manage the database. The information can be well displayed. The user interface should be friendly to the user.

The platform interface can be designed as following:

\begin{tabular}{|c|c|c|}
\hline menu & Sub-menu & function \\
\hline \multirow{3}{*}{ System manage } & administrator & Login, password, change user, \\
\hline & Professional user & Add, modify, delete, search \\
\hline & Common user & Add, modify, delete, search \\
\hline \multirow{3}{*}{ Reserve manage } & Reserve operation & Add, modify, delete, replace \\
\hline & $\begin{array}{l}\text { National Ecological } \\
\text { Zone }\end{array}$ & $\begin{array}{l}\text { Lushan, GuanShan Jinggangshan Jiulianshan Jiuling Matoushan } \\
\text { mountain Qivun cymbal mount Wuyishan }\end{array}$ \\
\hline & $\begin{array}{l}\text { Provincal Ecological } \\
\text { Zone }\end{array}$ & $\begin{array}{l}\text { Yao, Wuyuan, Liao River giant salamander, Ruichang of Taxus } \\
\text { chinensis... }\end{array}$ \\
\hline \multirow{2}{*}{ Plants data } & Common operation & Add, modify, delete, Import , export \\
\hline & Reference rule & Protection list (IUCN Redbook, Chinese species red list ...) \\
\hline Speciemens data & & Add, modify, delete, Import , export, icture operation \\
\hline Position info & & Soil sampling,Investigation route,Specimen collection \\
\hline Query & & $\begin{array}{l}\text { Query options button,Query after change(increase the field, cut } \\
\text { field),Fuzzy query,Precise query,Export Query result }\end{array}$ \\
\hline Theme & & Add Layer ,Delete,Move, overlap,Layer switch,et al. \\
\hline View & & $\begin{array}{l}\text { Legend (including the module to change the font size, filling, } \\
\text { linear size, direction, etc.), decoration,Auto Label,Scale control }\end{array}$ \\
\hline Help & & Version, User's Manual \\
\hline
\end{tabular}

\section{Conclusion}

Based on the data design and the interface design, the endangered plants information platform is quickly built by $\mathrm{C}++$ and $\mathrm{AO}$ software. The information can easy to be operated by some kinds of user. The whole watershed endangered plants information can be collected frequently. With the new reserve of Poyang Lake watershed application, more and more information of plants can be showed through the platform.

\section{Acknowledgement}

In this paper, the research was supported by the National support program of Jiangxi Province (Project No. 2011BAC13B01) and Ganpo 555 Engineering Project from Jiangxi Province (Project No. 20121BBE50019).

\section{References}

[1] ZHOU Sai-Xia, GAO Pu-Xin. Investigation of Rare and Endangered Plants in Jiangxi Province.[J] Journal of Plant Science , 2004, 22(5): 428-432. 
[2] Xie Guo-wen . Resource and protection of rare and endangered plants in Jiangxi province.[J] Plants resouce and environment, 1994, 3(1): 52-55.

[3] The editorial board of flora in Jiangxi. Flora of Jiangx Province( The first version) [M]. Nanchang: Jiangxi science and Technology Press, 1993.

[4] National Environmental Protection Bureau and Plant research Institute of Chinese Sciences Academy . China rare and endangered species of plants (first volume) [M]. Beijing: Science Press, 1987

[5] The State Council of the people's Republic of China. The national key protected wild plants (the first batch)[D]. Journal 1999(2): $4 \sim 11$.

[6] Lee En-xiang. Status analysis of rare and endangered plants of Jiangxi Province http://www.360doc.com/content/11/0219/12/2684624_94282956.shtml 